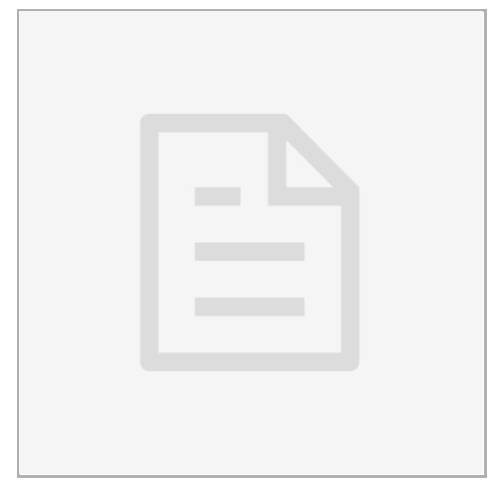

AUG 22, 2020

\section{(3) Copy of Detection of total and faecal coliforms in the oysters}

Sade Aisha Folashade John ${ }^{1}$, Patrick E. Akpaka , Chandrashekhar Unakal $^{1}$, Arvind Kurhade ${ }^{1}$, Angel Justiz-Vaillant ${ }^{1}$

IUniversity of the West Indies St. Augustine
Angel A Justiz-Vaillant

University of the West Indies St. Augustine

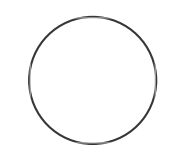

\section{open ठaccess}

\section{DOI:}

dx.doi.org/10.17504/protocol s. io. bj6gkrbw

Protocol Citation: Sade Aisha Folashade John, Patrick E. Akpaka, Chandrashekhar Unakal, Arvind Kurhade, Angel Justiz-Vaillant 2020. Copy of Detection of total and faecal coliforms in the oysters. protocols.io

https://dx.doi.org/10.17504/p rotocols.io.bj6gkrbw

License: This is an open access protocol distributed under the terms of the Creative Commons Attribution License, which permits unrestricted use, distribution, and reproduction in any medium, provided the original author and source are credited

Protocol status: Working We use this protocol and it's working

Created: Aug 22, 2020

Last Modified: Aug 22, 2020

PROTOCOL integer ID: 40872 


\section{ABSTRACT}

Enterobacteriaceae the leading cause of gastroenteritis. These gram-negative bacteria from species like Escherichia, Shigella, Salmonella, Vibrio and Helicobacter etc are among those that cause severe disease in consumers, especially those that indulge in uncooked seafood. Oysters have been shown to harbour these pathogenic organisms, which pose a major health risk. Numerous outbreaks of gastroenteritis due to oyster consumption have been reported worldwide because of the enteric bacteria as well as viral pathogen contamination

This research was conducted to identify the Enterobacteriaceae present in oysters sold by vendors in Trinidad. During a five-month period (the rainy season, May September), a total of 156 oyster samples (comprising 104 oysters samples and 52 water samples of the prepared, unprepared oyster cocktails plus the water used by vendors) were analysed. These samples were collected from roadside vendors operating near to the coastal line of the Western part of Trinidad These were processed at the microbiology unit of the Department of Para-clinical Sciences of the University of the West Indies, St. Augustine using standard microbiology techniques. The antibiotic susceptibility profiles of the recovered organisms were performed using the Kirby Bauer method for the following antibiotics- Tetracycline, Ampicillin, Trimethoprim-Sulfamethoxazole, Cefuroxime and Ceftazidime. The SPSS 21 programme was used to analyse the biometric data and a chi-square test was used to determine if there was any significant difference between the kinds of preparation cocktails with respect to the coliform and organisms found.

Results of the 104 oyster samples tested, 112 isolates were obtained, $13.4 \%$ (15/112) were E.coli of which $0.1 \%(1 / 15)$ was the $0157:$ H7 strain; $72.3 \%(81 / 112)$ were Shigella species of which $27.2 \%$ (22/81) were Shigella dysenteriae; $14.3 \%$ (16/112) were Salmonella species of which $25 \%$ (4/16) were Salmonella cubana. The susceptibility profiles of the organisms revealed that $86.5 \%$ of Shigella, $100 \%$ of E.coli and $93.7 \%$ of the Salmonella were resistant to multiple antibiotics. With the recovery of these organisms from these samples, the health of the Trinidadian and foreign consumers of mangrove oysters is at risk particularly from Shigella, E.coli and Salmonella species. As a result, there should be an increased need for public awareness as well as regulations by the Ministry of Health to be made so that illness from these hazardous Enterobacteriaceae can be prevented.

The meat ( 10 oysters per cup) of the unprepared oysters was blended with $25 \mathrm{ml}$ of sterile distilled water and $25 \mathrm{ml}$ of sterile peptone water using a sterilized blender (the blender was washed with antibacterial soap as well as bleach and rinsed with sterile distilled water along with $70 \%$ ethanol before autoclaving prior to each use). This was repeated for the meat from the prepared oysters. Each homogenate was then poured into a sterile $100 \mathrm{ml}$ flask using a sterilized funnel and filter paper $205 \mu \mathrm{m}$ thick and then poured into a sterile $100 \mathrm{ml}$ beaker. The filtered homogenate was then used to perform the Spread Plate Method for the total and fecal coliform on Nutrient agar and EMB agar respectively: 
2 A sterile graduated Pasteur pipette was used to dilute $1 \mathrm{ml}$ of sample water in a sterile test-tube of $9 \mathrm{ml}$ sterile distilled water and vortexed for 5 seconds. Then, using another sterile graduated Pasteur pipette, $1 \mathrm{ml}$ of this diluted sample was further diluted in $9 \mathrm{ml}$ sterile distilled water in another sterile test-tube, vortexed for 5 seconds and so on until 10 serial dilutions were achieved.

3 Ten (10) plates were labelled according to the sample number and desired dilution.

4 Using a new sterile graduated Pasteur pipette $0.1 \mathrm{ml}$ drop of the desired serial dilution was placed onto the centre of the surface of the agar plate.

5 Then using a sterile plastic L-shaped spreader, the sample was spread over the surface of the agar, carefully rotating the Petri Dish underneath at the same time. The L-shaped spreader was then discarded.

6 The plate was then inverted and incubated overnight at $34^{\circ} \mathrm{C}$.

7 This was done in duplicate and plates with the best/significant single colonies were chosen, ie; those that grew 30-200 single colonies.

8 The procedure was repeated for each serial dilution, so that each plate had a different dilution.

9 -After incubation, in order to easily count the colonies, the plates were divided into quadrants with a marker on the underside of the plate.

10 The colonies grown were then counted manually. The dilution that showed to have the best countable colonies was $10^{\wedge}-4$. 
11 The following equation was used: No. colonies $/ 0.1 \mathrm{ml}$ plated divided by $10^{\wedge}-\mathrm{X}$ and the results expressed as Colony Forming Units/0.1 millimetre $x 10\left(\mathrm{CFU} / 0.1 \mathrm{ml} \times 10^{\wedge} 4\right)$ in the range $<$ or $>200$ for the total and faecal coliform.

12 This method was repeated per vendor. 